\title{
Management of acute fever in children: Guideline for community healthcare providers and pharmacists
}

\author{
R Green, ${ }^{1}$ MB BCh, DCH, FCPaed (SA), DTM\&H, MMed (Paed), FCCP, PhD, Dip Allergol (SA), FAAAAI, FRCP; \\ P Jeena, ${ }^{2}$ FCP (Paeds), Cert Pulmonology; S Kotze, ${ }^{3} \mathrm{MB}$ ChB; H Lewis, ${ }^{4} \mathrm{MB}$ ChB, MMed (Paed); D Webb, ${ }^{5}$ BSc (Hons), MB BCh; \\ M Wells, ${ }^{6-8} \mathrm{MB}$ BCh, MSc (Med), FCEM (SA) \\ ${ }^{1}$ Department of Paediatrics and Child Health, University of Pretoria, South Africa \\ ${ }^{2}$ Department of Paediatrics and Child Health, University of KwaZulu-Natal, Durban, South Africa \\ ${ }^{3}$ Drs Esterhuysen, Serfontein, Venter \& Associates Inc., Emergency Department, Netcare Unitas Hospital, Pretoria, South Africa \\ ${ }^{4}$ Private Practice, Netcare Unitas Hospital, Pretoria, South Africa \\ ${ }^{5}$ Pattacus Medical Consulting, Johannesburg, South Africa \\ ${ }^{6}$ Division of Emergency Medicine, University of the Witwatersrand, Johannesburg, South Africa \\ ${ }^{7}$ Emergency Department, Netcare Union Hospital, Johannesburg, South Africa \\ ${ }^{8}$ Department of Emergency Medicine, Helen Joseph Hospital, Johannesburg, South Africa
}

Corresponding author: R Green (robin.green@up.ac.za)

Fever is a normal physiological response to illness that facilitates and accelerates recovery. Although it is often associated with a self-limiting viral infection in children, it may also be a presenting symptom of more serious conditions requiring urgent medical care. Therefore, it is essential to distinguish between a child with fever who is at high risk of serious illness and who requires specific treatment, hospitalisation or specialist care, and those at low risk who can be managed conservatively at home. This guideline aims to assist pharmacists, primary healthcare workers and general practitioners in risk-stratifying children who present with fever, deciding on when to refer, the appropriate use of antipyretic medication and how to advise parents and caregivers.

S Afr Med J 2013;103(12):948-954. DOI:10.7196/SAMJ.7207

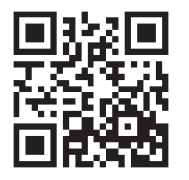

\section{Introduction}

Fever is a normal physiological response to illness that facilitates and accelerates recovery. Although there is no evidence that children with fever are at increased risk for adverse outcomes, fever in children is one of the most common reasons for parents or caregivers to seek medical attention for their child. It is frequently a cause for concern among parents and healthcare providers who fear that it may be associated with increased morbidity, such as seizures, brain damage or death. ${ }^{[1,2]}$ Furthermore, there is confusion about how and whether to manage fever. Antipyretics are frequently prescribed or purchased over-the-counter (OTC), specifically to bring down body temperature in an ill child, ${ }^{[2-5]}$ paracetamol and ibuprofen being the most frequently purchased OTC medicines for children. ${ }^{[3]}$

Although fevers are often a presenting symptom of a self-limiting viral infection, they are also associated with serious bacterial infections, such as meningitis and pneumonia, and other non-infective illnesses. Therefore, the underlying illness causing the fever needs to be determined and it is essential to be able to distinguish between a child with fever who is at high risk of serious illness and a child who requires specific treatment, hospitalisation or specialist care, and those at low risk who can be managed conservatively at home. This is not only true for clinicians, but also for pharmacists and pharmacy workers, who may be the first to see the ill child or caregiver.

This guideline has been developed to assist pharmacists, primary healthcare workers and general practitioners in risk-stratifying children who present with fever, deciding on when to refer, the appropriate use of antipyretic medication and how to advise parents and caregivers.

\section{Methods}

A PubMed search was performed to identify recent international guidelines and publications on the management of childhood fever. After review, a multidisciplinary group of clinicians who treat children attended a discussion forum to develop recommendations that are concise and simple to follow, based on the available evidence and their own clinical experience. Standard levels of evidence were assigned to support the recommendations as follows: $(A)$ at least two randomised trials; $(B)$ single randomised clinical trial or large non-randomised studies; and $(C)$ consensus opinion of the experts based on observational studies and clinical experience. Therefore, the guidelines offered here do not constitute inflexible treatment recommendations.

\section{Definition of fever and general principles}

- Fever is defined as a body temperature $\geq 38^{\circ} \mathrm{C}$. (Evidence B)

- Fever in itself is not detrimental, but rather a normal physiological response to infection or illness. In the absence of a diagnosis, treatment with the sole aim of reducing temperature is inappropriate and some febrile children will recover more quickly if the fever is not treated. ${ }^{[1,2]}$ (Evidence B)

- Most fevers are due to a self-limiting viral infection, but bacterial infections and other causes must be excluded. ${ }^{[1]}$

- Serious bacterial infection is more common in young children.

- Any fever in a child aged $<3$ months is significant and should be thoroughly investigated and referred to specialist care if the source of the fever cannot be found. 


\section{Measurement of body temperature}

- Body temperature should be measured in the ear using an infrared tympanic thermometer, or in the axilla. (Evidence B)

- Oral and rectal routes should not be used to measure body temperature in a child.

- Re-usable thermometers should be washed between use.

\subsection{Axillary measurement}

- Do not measure temperature directly after bathing.

- Ensure that the child's axilla is dry.

- If using a glass thermometer, before placing it in the axilla, shake the thermometer until the liquid is below the $36^{\circ} \mathrm{C}$ line. (Evidence C)

- Place the tip of the thermometer in the armpit and lightly press the child's elbow against the chest to close the tip of the thermometer in the armpit.

- Read the temperature:

- If using a digital thermometer: when the indicator sound ('beep') is heard.

- If using a glass thermometer: after $3 \mathrm{~min}$.

\subsection{Infra-red tympanic (ear) measurement}

- Attach a new lens filter to the tip of the thermometer each time it is used.

- Turn on the thermometer.

- Gently pull backwards (posteriorly) on the ear lobe to open the ear canal.

- Insert the probe of the thermometer into the ear canal and press the activation button until the beep is heard.

- Remove the thermometer from the ear and read the temperature on the LCD screen.

\section{Assessment of the child with fever at the pharmacy}

Algorithm 1 (Fig. 1) presents a simple systematic approach to assist with identifying a child with fever who requires referral to medical care.

\section{Medical history and examination by a clinician}

Fever is not a diagnosis, but a symptom of illness. A diagnosis of the underlying illness is essential to institute appropriate treatment.

\subsection{History}

Ask about:

- Fever: onset, duration, continuous or intermittent, response to general measures or medication.

- Associated signs and symptoms.

- Recent use of antibiotics.

- Recent vaccinations (within $48 \mathrm{~h}$ ) and vaccination history.

- Recent travel.

- Health of other family members, exposure to sick individuals, crèche/school.

- Previous illnesses (including immunodeficiency and chronic illnesses).

- Activity level.

\subsection{Examination}

- Initial impression: Features of life-threatening illness, ill-looking child and dehydration (Table 1).
- Vital signs: Temperature, heart rate, respiratory rate, capillary refill time, blood pressure (if facilities available).

- Assess risk of serious illness (Algorithm 3, Fig. 3).

- A complete examination is mandatory in all children presenting with fever, with particular attention to possible sources of bacterial infection (Table 2).

Approaches to the management of fever in children aged $<1$ month, 1 3 months and $>3$ months are shown in Algorithms 2 and 3 (Figs 2 and 3).

\section{General considerations for medical care (Evidence B)}

- The degree of temperature reduction in response to antipyretic medication is not predictive of the presence or absence of bacteraemia. ${ }^{[6]}$

- Do not administer antibiotics unless there is a clear indication of bacteraemia. ${ }^{[1]}$

- Empirical antibiotics for possible occult bacteraemia in children $>3$ months of age does not confer any significant advantage. ${ }^{[6]}$

- If the child has signs of severe sepsis or septic shock, parenteral antibiotics should be administered within the first hour of healthcare contact.

- Provide general advice (Table 4 and Section 11) for all parents, especially those who are unlikely to return for follow-up (because of, e.g., lack of transport, parental perception that the child is not that ill, no telephone).

\section{Discomfort caused by pain and fever}

- Discomfort during a febrile illness is often due to associated pain; e.g. myalgia, sore throat, headache.

- Antipyretics (ibuprofen and paracetamol) may be considered to improve comfort (with accompanying improvements in feeding activity and irritability), because they may also provide relief from pain and may reduce the risk of dehydration. ${ }^{[2]}$

\section{Antipyretic medication}

- Antipyretics should be used to make the child more comfortable and not used routinely with the sole aim of reducing the temperature..$^{[1,2]}$

- The use of antipyretic medication and attention to the fever must not detract from monitoring the child's activity and level of consciousness (as an indicator of worsening illness) and paying attention to adequate hydration.

- Both paracetamol and ibuprofen are safe and effective for shortterm use in children. ${ }^{[2,8-14]}$ (Evidence A)

- The practices of combining or alternating paracetamol and ibuprofen have limited value and are not recommended. ${ }^{[15,16]}$ (Evidence B)

- Mefenamic acid is registered for use from 6 months of age and may be an alternative non-steroidal anti-inflammatory (NSAID) to ibuprofen in children with fever. The recommended dose is $6.5 \mathrm{mg} / \mathrm{kg}$ of body weight, not more than three times daily (Evidence B). Care should be taken to avoid overdosing, which has been associated with adverse effects. ${ }^{[17,18]}$

- Dose of antipyretic medication in children should be accurately based on body weight and should not merely be estimated (Tables 5 - 7). For accurate dosing, liquid medicines should be administered with a syringe.

- Contraindications to and precautions in the use of antipyretic drugs in children are listed in Table 8. 


\section{GUIDELINE}

\section{Ask the parent/carer:}

About the child*

1. Is the child older than 3 months?

2. Is the child eating and drinking normally? ${ }^{\ddagger}$

3. Is the child behaving normally?

4. Is the child breathing normally?
About the symptoms

5. Has the fever been present for more than 2 days?

6. Has the child had convulsions?

7. Are you very worried about the child's health?

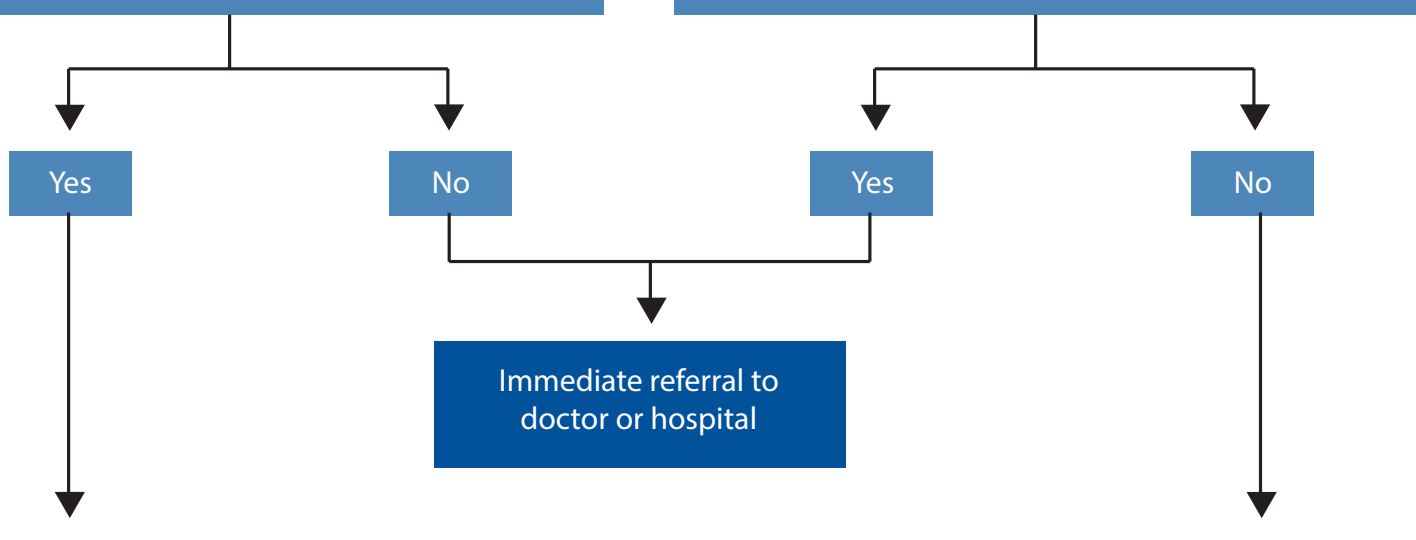

Look at the child for danger signs: ${ }^{\dagger}$

1. Is the child lethargic or unconscious?

2. Is the child inconsolably irritable?

3. Does the child have signs of dehydration or shock? (Table 1)

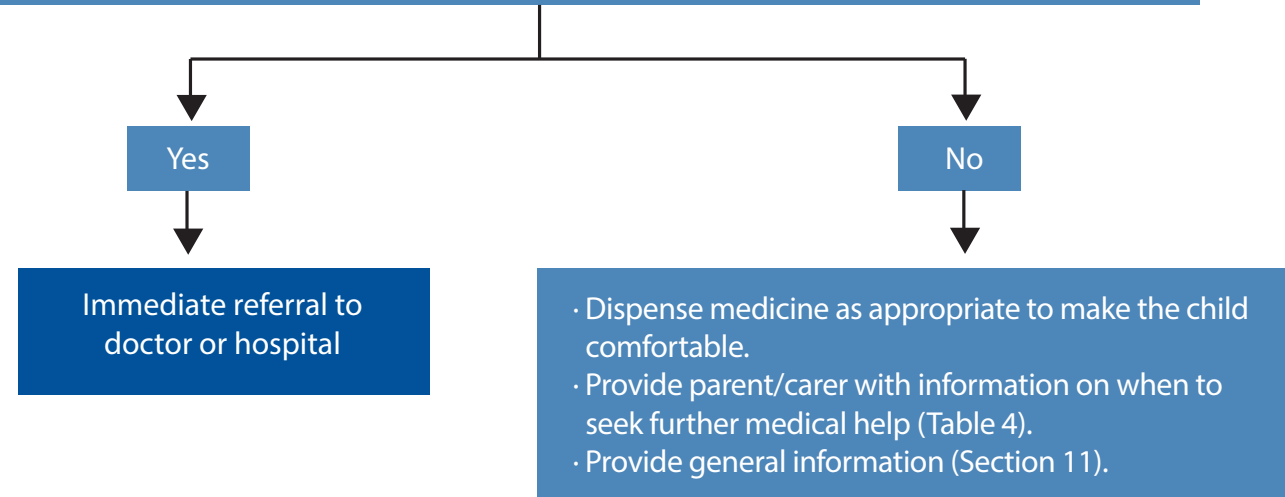

Fig. 1. Algorithm 1: Assessment of the child with fever at the pharmacy (Evidence B). ${ }^{*} A$ 'No' answer to any of these questions indicates immediate referral to a doctor or clinic. ${ }^{\prime} A$ 'Yes' answer to any of these questions/observations indicates immediate referral to a doctor or clinic. ${ }^{*}$ Children with persistent vomiting should be referred. In a child who is awake and alert, smiling, staying awake, strong crying or not crying are normal behaviours.

- Aspirin should not be used in children younger than 12 years of age, because of the risk of Reye's syndrome. (Evidence A)

- The use of NSAIDs has been associated with an elevated risk of severe skin and soft-tissue infections in patients with varicella zoster virus infection. ${ }^{[19-21]}$ Therefore, paracetamol is recommended as the antipyretic of choice in children with chicken pox.

- Medicines containing combinations of NSAID(s), paracetamol, codeine and/or antihistamines should not be used in children. (Evidence B)

\section{Vaccination and fever (Evidence B)}

- Fever and a local reaction (pain, swelling, redness) are normal reactions to vaccination and are not harmful.

- Prophylactic administration of antipyretic drugs at the time of vaccination is associated with reduced antibody responses to vaccine antigens. ${ }^{[23]}$

- Antipyretic medication should not be administered either as a treatment for a local inflammatory reaction or fever, or prophylactically to prevent a local inflammatory reaction or fever. 
- Antipyretics may be considered to make the child more comfortable in the event of complications associated with vaccination, such as cellulitis or systemic complications.

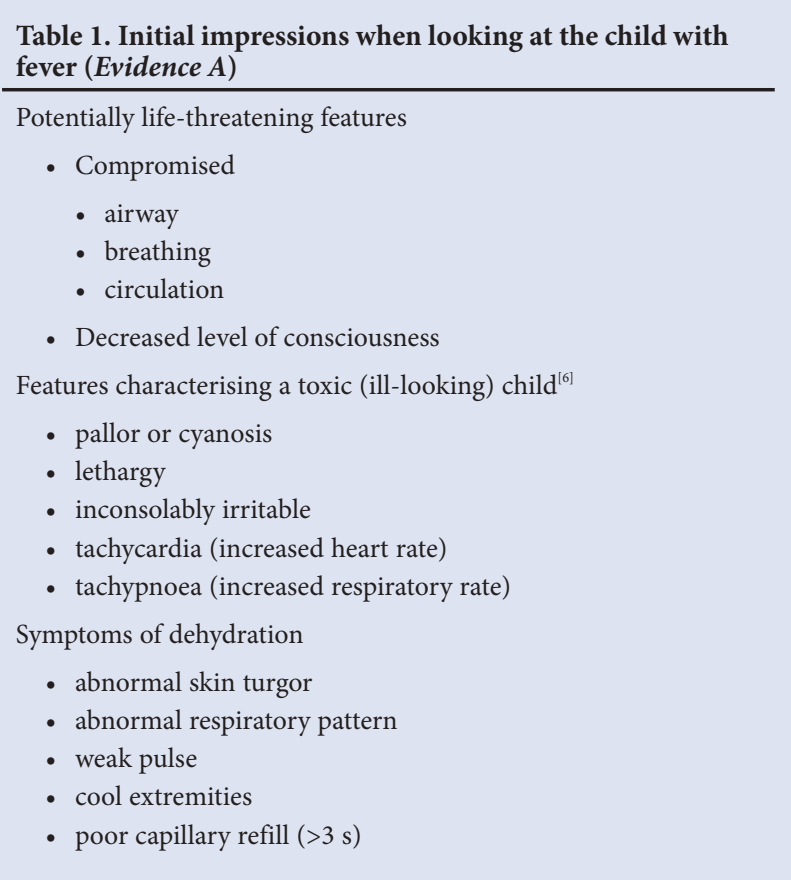

Table 2. Bacterial infections causing fever that must be excluded $^{[1,6]}$

Otitis media
Urinary tract infection
Streptococcal pharyngitis
Pneumonia
Skin and soft-tissue infections (e.g. impetigo, cellulitis)
Meningitis
Bone and joint infections
Enteritis
Septicaemia/bacteraemia
Sinusitis

\section{Advice for parents caring for the child at home}

Parents require clear instructions on how to manage and monitor the child at home and reassurance that fever itself does not necessarily require treatment, but is a symptom of an illness requiring a diagnosis to direct specific and appropriate treatment.

\subsection{Reassure parents with anxiety about the child's fever}

- Fever is not an illness, but a beneficial response of the body to illness.

- Most fevers are of short duration and are not harmful.

- Children with fever are not at increased risk of seizures, dehydration, brain damage or death.

- Body temperature during fever normally fluctuates and the fever will run its course.

- The fever will return until the illness is better.

- Strict control of fever is never required.

\subsection{Advise the parent on the management of} fever at home

- Tepid sponging is not recommended.

- Do not over-dress or under-dress the child, or wrap the child in heavy blankets.

- Encourage the child to drink fluids regularly (breast milk is best for breastfeeding children).

- To ensure that you are using the correct medication at the correct dose, speak to your doctor or pharmacist before administering medication for fever.

- Check the child during the night, but do not wake the child just to administer antipyretic medication.

- Seek further medical advice if the fever does not get better within $48 \mathrm{~h}$, or if the child's condition worsens (Table 4).

\subsection{Give clear instructions on how to} administer medication

- Correct dose.

- How to measure the dose.

- How often to administer a dose.

- Warn parents not to exceed the prescribed dose or dosing interval.

- Shake the bottle before pouring.

- Never measure medicine using a household teaspoon or tablespoon - use only the measuring device provided. Unless the medicine comes with a measuring device, caregivers should be provided with

Table 3. Age-specific vital signs and laboratory values: Cut-off values for the definitions of SIRS, infection, sepsis, severe sepsis and septic shock ${ }^{*}$

\begin{tabular}{|c|c|c|c|c|c|}
\hline \multirow[b]{2}{*}{ Age group } & \multicolumn{2}{|c|}{ Heart rate (beats $/ \mathrm{min})^{\dagger}$} & \multirow{2}{*}{$\begin{array}{l}\text { Respiratory rate } \\
{\text { (breaths } / \mathrm{min})^{\dagger}}\end{array}$} & \multirow{2}{*}{$\begin{array}{l}\text { Leukocyte count } \\
\left(\times 10^{3} \text { cells } / \mathrm{mm}^{3}\right)^{\dagger}\end{array}$} & \multirow{2}{*}{$\begin{array}{l}\text { Systolic blood } \\
\text { pressure }(\mathrm{mmHg})^{\dagger}\end{array}$} \\
\hline & Tachycardia & Bradycardia & & & \\
\hline 0 days - 1 week & $>180$ & $<100$ & $>50$ & $>34$ & $<65$ \\
\hline 1 week - 1 month & $>180$ & $<100$ & $>40$ & $>19.5$ or $<5$ & $<75$ \\
\hline 1 month - 1 year & $>180$ & $<90$ & $>34$ & $>17.5$ or $<5$ & $<100$ \\
\hline $2-5$ years & $>140$ & NA & $>22$ & $>15.5$ or $<6$ & $<94$ \\
\hline $6-12$ years & $>130$ & NA & $>18$ & $>13.5$ or $<4.5$ & $<105$ \\
\hline $13->18$ years & $>110$ & NA & $>14$ & $>11$ or $<4.5$ & $<117$ \\
\hline
\end{tabular}


an appropriate syringe or measuring spoon whenever medicine for a child is dispensed.

- Never allow children to drink medicines straight from the bottle.

- Store all medicines out of the reach of children.
11.4. Advise parents on the correct use of antipyretic medication

- Antipyretics should be used to make the child more comfortable and not used routinely with the sole aim of reducing the temperature.

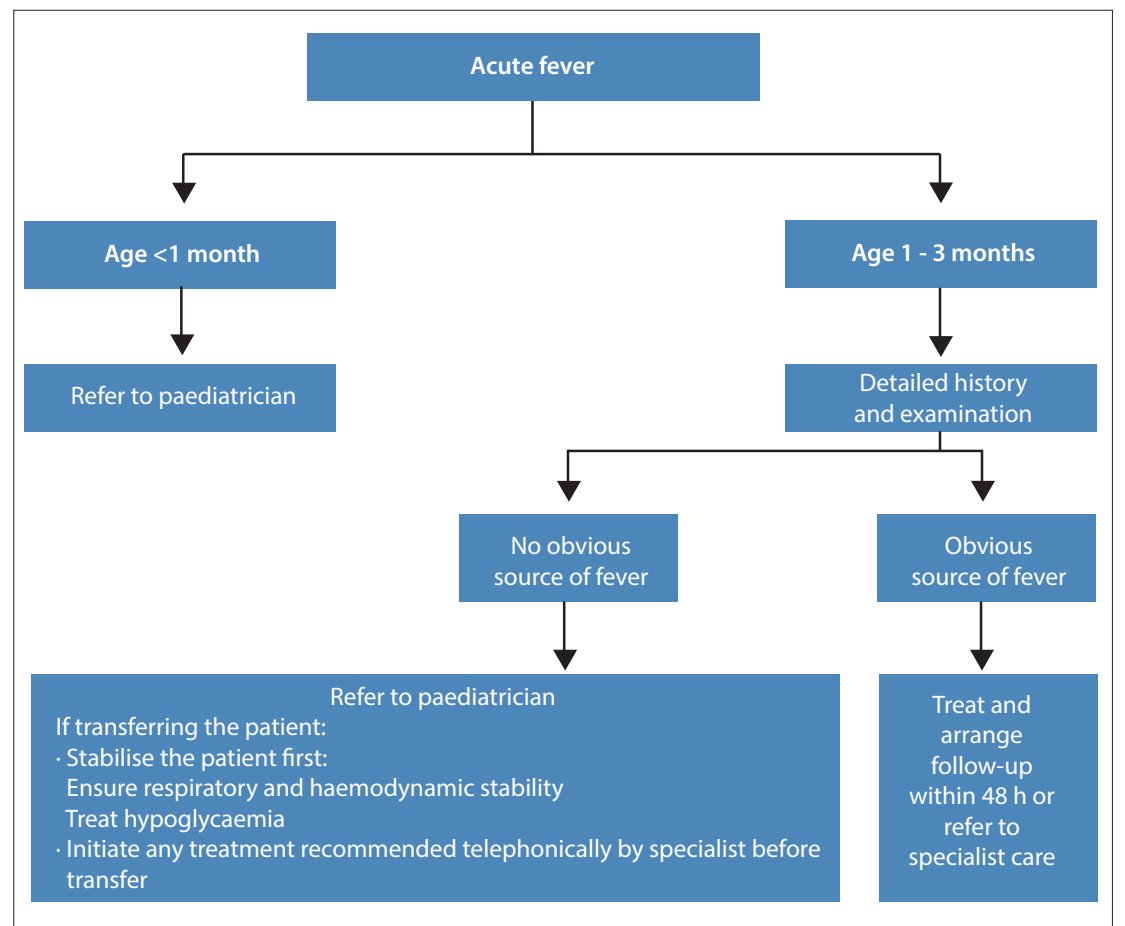

Fig. 2. Algorithm 2: Investigation of acute fever in children aged 0 - 3 months.

Table 4. Indications to seek further medical assistance when caring for the child at home (Evidence A)

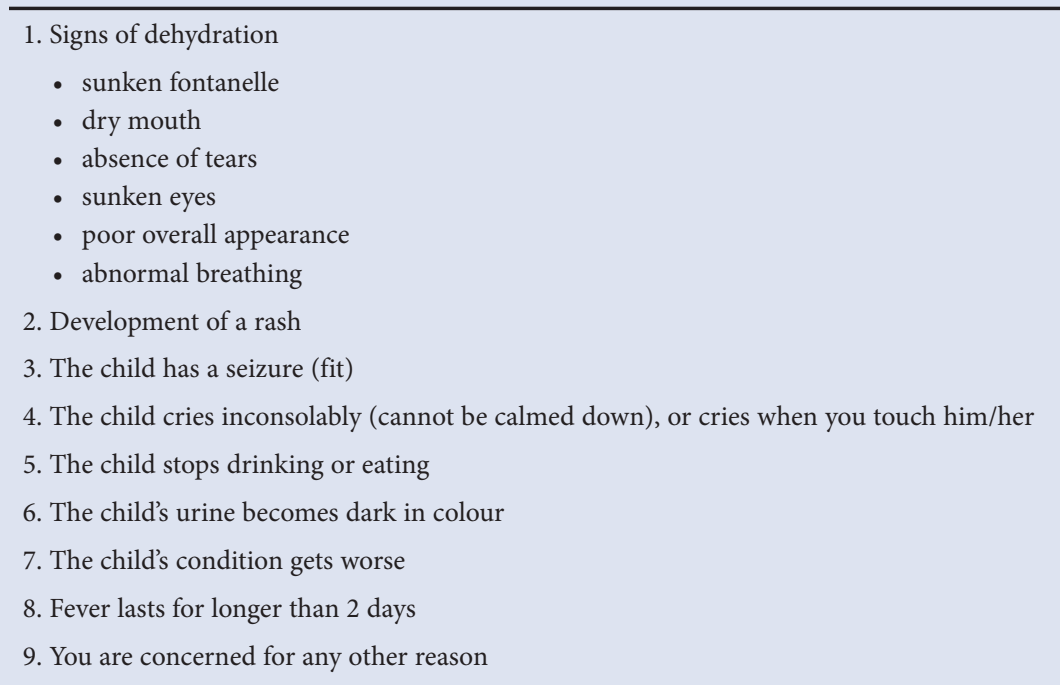

- Antipyretics do not prevent febrile convulsions and should not be used specifically for this purpose. ${ }^{[1]}$

- Doses should be measured carefully to avoid over- or under-dosing.

- Antipyretic medication starts to work within $1-3 \mathrm{~h}$

- If the temperature does not come down after one dose, do not administer another dose immediately. Wait for the appropriate dosing interval to pass and only give another dose at the correct time.

- If the child vomits immediately after taking a dose of medicine, another dose may be given.

- Antipyretic medication will not return the body temperature to normal unless the fever was low to start with.

- Sleeping children should not be awakened solely to administer antipyretics.

- Avoid combination products and 'cough and cold medicines', which complicate dosing and may increase the risk of overdose and side-effects.

- Antipyretic medication should not be administered for longer than 2 days without consulting a doctor.

\subsection{Provide written instructions about follow-up}

\section{Conclusion}

Although fever in children is often benign and self-limiting, the cause of the fever can present a diagnostic challenge to the healthcare provider. However, with timeous identification, the child at risk of serious illness may be quickly referred and appropriately managed.

Parents and healthcare providers need to be reassured when the risk of serious illness is low, and the child should be managed appropriately at home with antipyretic medication if indicated to make the child more comfortable. Clear instructions to advise parents and caregivers about when to seek further care for their child will help to reduce the morbidity associated with childhood illnesses.

Conflict of interest. The development of this guideline was supported by an unconditional grant from Reckitt Benckiser. The sponsor did not participate in the development or writing of the guideline.

Table 5. Dose of antipyretic medication for children older than 3 months of age ${ }^{[2,22]}$ (Evidence B)

\begin{tabular}{llll}
\hline & Oral dose $(\mathbf{m g} / \mathbf{k g})$ & Dose frequency & Maximum daily dose $(\mathbf{m g} / \mathbf{k g})^{*}$ \\
\hline Ibuprofen & 10 & every $6 \mathrm{~h}$, as necessary & 40 \\
Paracetamol & $15($ up to $1 \mathrm{~g})$ & every $4-6 \mathrm{~h}$, as necessary & $90(4 \mathrm{~g}$ in total) \\
*Do not exceed this dose within a 24-h period. & & &
\end{tabular}




\section{GUIDELINE}

\section{Detailed history and examination}

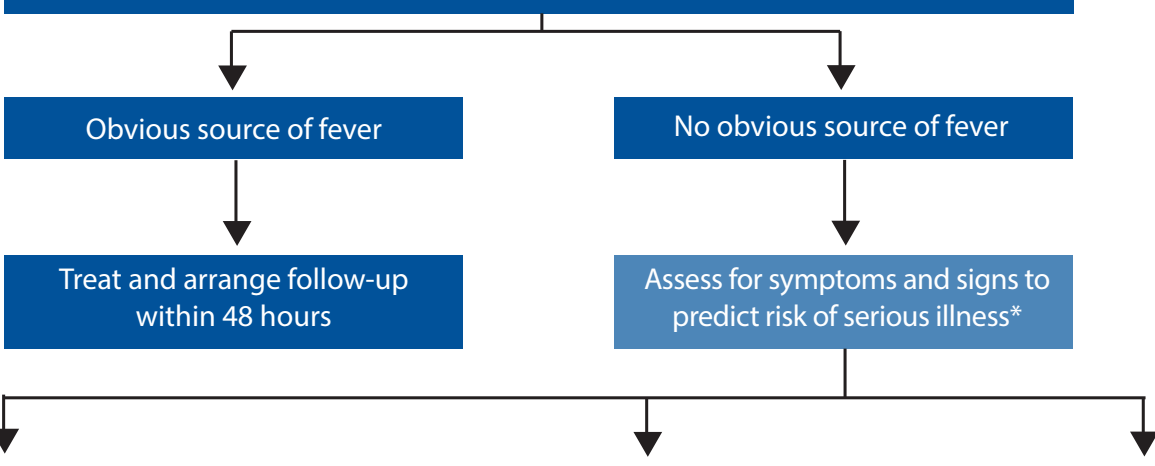

\section{High risk}

- Unable to rouse or if roused does not stay awake - Weak, high-pitched or continuous cry

- Pale/mottled/blue/ashen

- Reduced skin turgor

- Moderate or severe chest indrawing

- Respiratory rate $>60$ breaths/min

- Grunting

- Bulging fontanelle

- Appearing ill to a healthcare professional (Table 1)

- Age 3 - 6 months and temperature $\geq 39^{\circ} \mathrm{C}$

- Non-blanching rash

- Neck stiffness, focal neurological signs

- Focal seizures

- Bile-stained vomiting

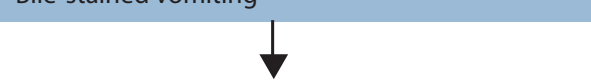

Urgent referral to paediatric specialist or

hospital

-Stabilise the patient first:

Ensure respiratory and haemodynamic stability

Treat hypoglycaemia

- If time from referral to hospital is $>1$ hour:

Give first dose of an appropriate intramuscular antibiotic

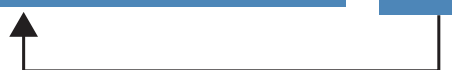

\section{Intermediate risk}

-Wakes up only with prolonged stimulation

Decreased activity

- Poor feeding in infants

Not responding normally to social cues, no smile

- Dry mucous membranes

- Reduced urine output

Pallor reported by parent or carer

- Nasal flaring

Tachypnoea - Respiratory rate:

Age $3-12$ months: $>50$ breaths $/ \mathrm{min}$ Age 12 - 59 months: $>40$ breaths $/ \mathrm{min}$

- A new lump larger than $2 \mathrm{~cm}$

- Non weight bearing, not using an extremity

- Other signs of dehydration

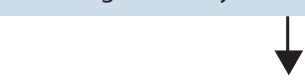

Abnormal physiology (Table 3)

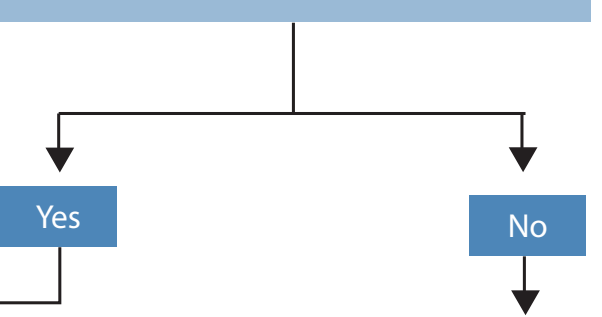

Reassurance and home management

- Advise follow-up if symptoms

do not resolve within 24 - 48

hours

General advice on when to

seek further medical help

(Table 4)

Refer, or telephonic consultation with specialist

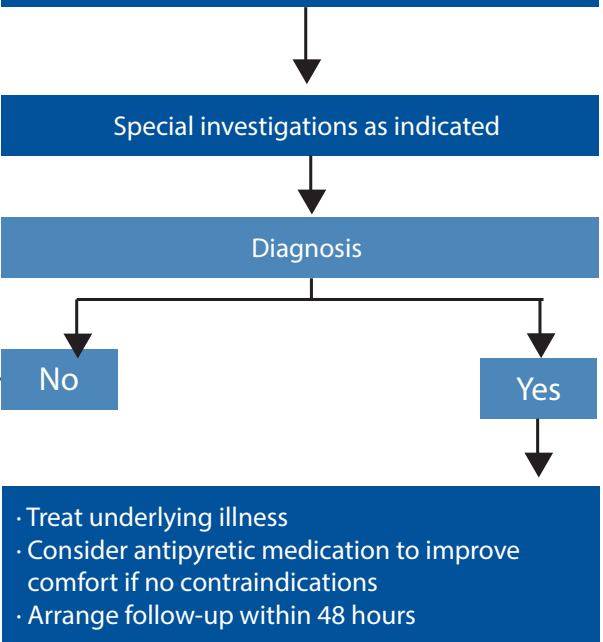

Fig. 3. Algorithm 3: Investigation of acute fever in children $>3$ months of age. ${ }^{*}$ Risk stratification adapted from National Institute for Health and Clinical Excellence (NICE). ${ }^{[1]}$ 
Table 6. Dose by body weight for oral liquid: Ibuprofen $100 \mathrm{mg} / 5 \mathrm{ml}$

\begin{tabular}{ll}
\hline Body weight $(\mathbf{k g})$ & Medicine measure $(\mathbf{m l})^{*}$ \\
\hline 6 & 3 \\
9 & 4.5 \\
12 & 6 \\
15 & 7.5 \\
18 & 9 \\
21 & 10.5 \\
24 & 12 \\
27 & 13.5 \\
30 & 15 \\
33 & 15 \\
36 & 15 \\
39 & 15 \\
${ }^{*}$ Administer not more frequently than every 6 h.
\end{tabular}

Table 7. Dose by body weight for oral liquid: Paracetamol $120 \mathrm{mg} / 5 \mathrm{ml}$

\begin{tabular}{ll}
\hline Body weight $\mathbf{( k g )}$ & Medicine measure $(\mathbf{m l})$ \\
\hline 6 & 3.7 \\
9 & 5.6 \\
12 & 7.5 \\
15 & 9.4 \\
18 & 11.2 \\
21 & 13.1 \\
24 & 15 \\
${ }^{*}$ Administer not more frequently than every 4 - $6 \mathrm{~h}$.
\end{tabular}

References

1. National Institute for Health and Clinical Excellence (NICE). Feverish Illness in Children - Assessment and Management in Children Younger than 5 Years. NICE Clinical Guideline 47. London, UK: NICE, 2007. Sullivan JE, Farrar $\mathrm{HC}$ on Drugs. Fever and antipyretic use in childen. Ped

3. Bárzaga Arencibia Z, Choonara I. Balancing the risks and benefits of the use of over-the-counter pain medications in children. Drug Saf 2012;35(12):1119-1125. [http://dx.doi.org/10.2165/11633620-00000]

4. Demir F, Sekreter O. Knowledge, attitudes and misconceptions of primary care physicians regarding fever in children: a cross sectional study. Ital J Pediatr 2012;38(1):40. [http://dx.doi.org/10.1186/1824-7288-38-40] Chiappini E, Parretti A, Becherucci P, et al. Parental and medical knowledge and management of fever in Italian pre-school Anildren. BMC Pediat 2012,12(1).97. [h/p//dx.doi.org/10.1186/1471-2431-12-97] Fhys 2001;64(7):1219-1226

Goldstein B, Giroir B, Randolph A; Members of the International Consensus Conference on Pediatric Sepsis. International pediatric sepsis consensus conference: Definitions for sepsis and organ dysfunction in pediatrics. Pediatr Crit Care Med 2005;6(1):2-8. [htpp://dx.doi.org/ 10.1097/01.PCC.0000149131.72248.E6]

8. Plaisance KL. Toxicities of drugs used in the management of fever. Clin Infect Dis 2000;31(Suppl 5):S219-S223. [http://dx.doi.org/10.1086/317518]

9. Goldman RD, Ko K, Linett LJ, Scolnik D. Antipyretic efficacy and safety of ibuprofen and acetaminophen in children. Ann Pharmacother 2004;38(1):146-150. [http://dx.doi.org/10.1345/aph.1 C391]

10. Perrott DA, Piira T, Goodenough B, Champion D. Efficacy and safety of acetaminophen vs ibuprofen for treating children's pain or fever: A meta-analysis. Arch Pediatr Adolesc Med 2004;158(6):521-526. [http:// treating childrens pain or fever: A me
dx.doi.org/10.1001/archpedi.158.6.521]

11. Pierce CA, Voss B. Efficacy and safety of ibuprofen and acetaminophen in children and adults: A meta-analysis and qualitative review. Ann Pharmacother 2010;4(3):489-506. [http://dx.doi.org/10.1345/aph.1M332]
and

12. Kauffman RE, Sawyer LA, Scheinbaum ML. Antipyretic efficacy of ibuprofen vs acetaminophen. Am J Dis Child 1992;146(5):622-625. [http://dx.doi.org/10.1001/archpedi.1992.02160170102024]

13. van Esch A, van Steensel-Moll HA, Steyerberg EW, et al. Antipyretic efficacy of ibuprofen and acetaminophen in children with febrile seizures. Arch Pediatr Adolesc Med 1995;149(6):632-637. [http:// dx.doi.org/10.1001/archpedi.1995.02170190042007]

14. Hay AD, Costelloe C, Redmond NM, et al. Paracetamol plus ibuprofen for the treatment of fever in children (PITCH): Randomised controlled trial. BMJ 2008;337:a1302. [http://dx.doi.org/10.1136/bmj.a1302] 15. Purssell E. Systematic review of studies comparing combined treatment with paracetamol and
ibuprofen, with either drug alone. Arch Dis Child 2011;96(12):1175-1179. [http://dx.doi.org/10.1136/ archdischild-2011-300424] 16. Pereira GL, Dagostini JMC, da Silva Dal Pizzol T. Alternating antipyretics in the treatment of fever in
children: a systematic review of randomized clinical trials. J Pediatr (Rio J) 2012;88(4):289-296. [http:// dx.doi.org/10.2223/JPED.2204]

17. Public Assessment Report for Paediatric Studies Submitted in Accordance with Article 45 of Regulation (EC) No1901/2006, as amended Mefenamic Acid UK/W/037/pdWS/001. http://www.hma.eu/fileadmin/ dateien/Human_Medicines/CMD_h_/Paediatric_Regulation/Assessment_Reports/Article_45_worksharing/Mefenamic_acid_-_Art.45_PublicAR.pdf (accessed 21 October 2013).

18. Smolinske SC, Hall AH, Vandenberg SA, et al. Toxic effects of nonsteroidal anti-inflammatory drugs in overdose: An overview of recent evidence on clinical effects and dose-response relationships. Drug Saf 1990;5(4):252-274. [http://dx.doi.org/10.2165/00002018-199005040-00003]

19. Mikaeloff Y, Kezouh A, Suissa S. Nonsteroidal anti-inflammatory drug use and the risk of severe skin and soft tissue complications in patients with varicella or zoster disease. Br J Clin Pharmacol 2007;65(2):203-209. [http://dx.doi.org/10.1111/j.1365-2125.2007.02997.x]

20. Dubos F, Hue V, Grandbastien B, et al. Bacterial skin infections in children hospitalized with varicella: A possible negative impact of non-steroidal anti-inflammatory drugs? Acta Derm Venereol 2008;88(1):26-30. [http://dx.doi.org/10.2340/00015555-0333]

21. Souyri C, Olivier P, GrolleauS, et al. Severe necrotizing soft-tissue infections and nonsteroidal anti-inflammatory drugs. Clin Exp Dermatol 2008;33(3):249-255. [http://dx.doi.org/10.1111/j.1365-2230.2007.02652.x]

22. World Health Organization. WHO Guidelines on the Pharmacological Treatment of Persisting Pain in Children with Medical Illnesses. Geneva: WHO, 2012. http://apps.who.int/medicinedocs/en/m/abstract/ Js19116en/ (accessed 21 October 2013)

23. Prymula R, Siegrist CA, Chlibeck R, et al. Effect of prophylactic paracetamol administration at time of vaccination on febrile reactions and antibody responses in children: Two open-label, randomised controlled trials. Lancet 2009;374(9698):1339-1350. [http://dx.doi.org/10.1016//0140-6736(09)61208-3]

Table 8. Contraindications and precautions to the use of antipyretic drugs in children ${ }^{[22]}$ (Evidence C)

\begin{tabular}{lll}
\hline & NSAIDs & Paracetamol \\
\hline Contraindications & Hypersensitivity, active peptic ulceration or upper GI bleeding, severe & \\
& renal failure, hepatic or cardiac failure & \\
Precautions & $\begin{array}{l}\text { Asthma, cardiac disease, dehydration, concomitant use of drugs that } \\
\text { increase risk of bleeding, previous peptic ulceration, coagulation defects, }\end{array}$ & $\begin{array}{l}\text { Hepatic impairment, renal } \\
\text { impairment, overdose }\end{array}$ \\
& allergic disorders, renal or hepatic impairment & \\
NSAIDs = non-steroidal anti-inflammatory drugs; GI = gastrointestinal.
\end{tabular}

